\title{
CICLOESTRATIGRAFIA: TEORIA E TÉCNICAS
}

\author{
MARTIN A. PERLMUTTER ${ }^{1}$, NILO CHAGAS DE AZAMBUJA FILHO²
}

\begin{abstract}
CYCLOSTRATIGRAPHY: THEORY AND TECHNIQUES This paper represents a summary of the state of the art of the Cyclostratigraphy and it has been divided into two parts. The first one deals with the theory in which the Cyclostratigraphy is based on, while in the second one will be discussed examples of applications in a sedimentary succession of the Oligocene-Miocene in age from the Campos basin.

Cyclostratigraphy is the subdivision of geologic studies that investigate cyclic depositional patterns. At present, there are two main areas of research that have been developed in cyclostratigraphy. The first area focuses on understanding how climatic and sedimentary processes interact with tectonic processes to produce the observed stratigraphic cycles. The second one focuses on the techniques of time measurement of cycles and the development of a geochronologic framework. In order to understand the causes and frequencies of stratigraphic cycles both areas need to be integrated. The comprehension of the impact of insolation cycles in the sedimentary cycles is extremely important in both regional and global scales to elaborate high resolution stratigraphic correlations and geochronologic frameworks, what can be achieved with the application of the cyclostratigraphy.
\end{abstract}

\begin{abstract}
Resumo Este trabalho é um sumário do estado da arte da Cicloestratigrafia, e foi dividido em duas partes. Nesta primeira parte, será apresentada a teoria em que se fundamenta a Cicloestratigrafia e algumas técnicas utilizadas para quantificação da periodicidade de ciclos sedimentares. Na segunda parte, será apresentada uma aplicação na seção sedimentar de idade Oligoceno-Mioceno da Bacia de Campos.

A Cicloestratigrafia é uma subdivisão dos estudos geológicos que investigam os padrões e a formação dos padrões sedimentares cíclicos. Atualmente, existem duas linhas de pesquisa que se desenvolveram no estudo da cicloestratigrafia. A primeira consiste em conhecer como os processos climáticos e sedimentares interagem com os processos tectônicos para produzirem os ciclos sedimentares observados no registro geológico. A segunda linha está focada em técnicas de medição do tempo de duração dos ciclos e do desenvolvimento de arcabouços geocronológicos de alta resolução temporal. Contudo, para entendermos as causas e as frequiências dos ciclos sedimentares, as duas áreas de pesquisa necessitam estarem integradas.

É vital para as correlações estratigráficas e para a elaboração de arcabouços geocronológicos de alta precisão a compreensão do impacto que um ciclo de insolação pode causar na variação de ciclos estratigráficos, tanto ao nível regional como global, o que pode ser obtido através das análises cicloestratigráficas.
\end{abstract}

INTRODUÇ̃̃̃ Vivemos num mundo onde existem vários tipos de ciclos previsíveis, ciclos lunares, solares e sazonais que refletem uma banda de freqüência dentro do nosso calendário e que estão associadas à rotação e aos ciclos orbitais da Terra e da Lua. Contudo, também existem outras frequiências associadas a variações orbitais, como a Banda de Freqüência de Milankovitch, cuja duração varia entre 10.000 e 500.000 anos, objeto de um crescente número de estudos sobre fenômenos geológicos repetitivos. Esses trabalhos fundamentam-se na teoria de Milankovitch (1941), que procura explicar as glaciações pleistocênicas através de variações do grau de insolação da Terra em função dos movimentos de precessão ( 19 a $23 \mathrm{Ka}$, onde $\mathrm{Ka}=1.000$ anos), obliqüidade (41 Ka) e excentricidade (100 e $413 \mathrm{Ka}$ ).

Com o desenvolvimento da pesquisa em sedimentos pleistocênicos, obtidos através de sondagens de programas internacionais como o DSDP e ODP, ficou demonstrada a perfeita correlação entre dados geológicos (sedimentológicos, paleontológicos e geoquímicos) e dađos orbitais (Hays et al. 1976, Imbrie et al. 1984). Entretánto, ainda persistem controvérsias a respeito de uma relação direta entre a sazonalidade do tamanho das massas de gelo e uma mudança conseqüente no clima a longa distância, como advogam Broecker \& Denton (1989). Esses autores preferem explicar que os ciclos glaciais foram dominados por reorganizações abruptas do sistema oceano-atmosfera, impulsionadas por mudanças orbitalmente induzidas no transporte de água doce, o qual teria influenciado a estrutura salina dos oceanos. Como conseqüência mudaria o padrão de circulação oceânica, causando mudanças na distribuição de calor na Terra, com naturais implicações climáticas.
Uma vez estabelecido que, no registro geológico do Pleistoceno, as variações orbitais têm um papel modulador, é de se esperar que, de algum modo, o mesmo possa ter ocorrido num passado mais distante, de modo que teríamos no registro geológico um marca-passo orbital com valores cronológicos de inestimável valor.

Este trabalho foi dividido em duas partes, visando atender as normas da Revista Brasileira de Geociências. Nesta primeira parte será apresentado um sumário do estado da arte da Cicloestratigrafia e na segunda parte será apresentada uma aplicação destas técnicas. Nos demais capítulos desta publicação serão apresentados outros exemplos da aplicação desta técnica em seções estratigráficas de bacias brasileiras, que possuem idades variando desde o Devoniano até o Terciário. Parte substancial do que será apresentado nas partes I e II é oriunda do trabalho apresentado por Perlmutter \& Azambuja Filho (2005) no capítulo 14 do livro editado por Eduardo Koutsoukos entitulado Applied Stratigraphy, publicado pela Springer, volume 23 - Topics in Geobiology.

HISTÓRIA Apesar do registro sedimentar ter sido interpretado como tendo padrões de sedimentação cíclica há mais de um século e os termos ciclo ou estratigrafia cíclica terem sido utilizados para descrever esses padrões por décadas, o termo Cicloestratigrafia foi utilizado apenas recentemente. Kalmykova et al. (1979) utilizou o termo num trabalho que descreve a sua aplicação no estudo de rochas marinhas de idade permiana na plataforma russa. Fischer (1986) utilizou o termo para descrever um método para correlacionar o tempo geológico com a estrati-

1 - Chevron Energy Technology Company, 1500 Louisiana St. Houston, Texas 77002, USA. mperlmutter@,chevron.com

2 - PETROBRAS - Centro de Pesquisas e Desenvolvimento Av Jequitibá, 950 - Cidade Universitária - Ilha do Fundão 21941 -598 - Rio de Janeiro, RJ, Brasil niloazambuja@petrobras.com.br 
grafia utilizando ciclos orbitais.

Perlmutter e Matthews (1989) também utilizaram o termo para descrever uma técnica desenvolvida em meados de 1980 no Centro de pesquisas da Texaco, com o objetivo de entender os efeitos dos ciclos orbitais nos sistemas deposicionais, lagos e nível do mar, para predizer a litoestratigrafia de uma determinada região.

A Cicloestratigrafia é uma subdivisão dos estudos geológicos que investigam os padrões e a formação dos padrões sedimentares cíclicos. Atualmente, existem duas linhas de pesquisa que se desenvolveram no estudo da cicloestratigrafia. Uma que foca em conhecer como os processos climáticos e sedimentares interagem com os processos tectônicos para produzirem os ciclos sedimentares observados no registro geológico. A segunda linha está focada em técnicas de medição do tempo de duração dos ciclos e do desenvolvimento de arcabouços geocronológicos de alta resolução temporal. Contudo, para entendermos as causas e as frequiências dos ciclos sedimentares as duas áreas de pesquisa necessitam estarem integradas (Perlmutter \& Azambuja Filho, 2005).

\section{PROCESSOS GEOLÓGICOS QUE ORIGINAM CICLI-} CIDADE SEDIMENTAR Três fatores importantes têm sido associados como causa da ciclicidade no registro sedimentar: variação do nivel do mar ou do lago; tectonismo, através de movimentos de subsidência ou soerguimento; e mudanças climáticas. A variação do nível do mar foi o primeiro fator a ser reconhecido como tendo potencial para criar sequiências sedimentares repetidas. Em 1874, Newberry sugeriu que a subida e descida do nível do mar produzia seqüências de afinamento do tamanho dos grãos para o topo e eram sobrepostas por seqüências que possuíam um aumento do tamanho do grão para cima. Em 1936, Wanless e Shepherd propuseram que a glacioeustasia e os ciclos climáticos a ela associados causaram os famosos Ciclotemas observados nas rochas sedimentares de idade paleozóica. Mais recentemente, foram desenvolvidas técnicas conhecidas como estratigrafia de seqüências, tendo como princípio as variações do nível do mar como controle dominante nos processos sedimentares marinhos e decorrentes padrões deposicionais (Vail et al. 1977; Goldhammer et al. 1987; Posamentier and Vail 1988).

As causas que são atribuídas para explicar as variações do nível do mar estão associadas com variações devido a mudanças do volume das cordilheiras meso-oceânicas, aos efeitos de fenômenos tectônicos de longa duração, a variações do volume das massas de gelo nas regiões polares, em especial na Antártida, a qual pode gerar um efeito tanto em longo prazo quanto em curto prazo. Adicionalmente, as variações do nível do mar podem também ter componentes tectônicos, de mais alta periodicidade, e climáticos.

Variações na subsidência ou no soerguimento de áreas fontes e em bacias sedimentares também têm sido identificadas como causas fundamentais para explicar a ocorrência de ciclos sedimentares (Williams 1891; Twenhofel 1932; Krynine 1942, Weller 1956; Bott and Johnson 1967; Veizer and Jansen 1985; Blair 1986). Essas mudanças induzidas por fenômenos tectônicos podem alterar a distribuição e localização de depocentros, taxas de erosão e de transporte de sedimentos em uma dada região. Os ciclos sedimentares produzidos por esses fenômenos normalmente possuem periodicidades que variam de dezenas de milhares de anos até dezenas de milhões de anos, contudo caracterizam-se por serem episódicos, mas não regulares, tendendo a ocorrer aleatoriamente no registro geológico.

Gilbert (1895) foi o primeiro autor a sugerir que a causa primária da formação dos ciclos sedimentares estava relacionada a mudanças climáticas. Posteriormente, vários autores recon- heceram também que a ocorrência regular de ciclos sedimentares estaria associada a mudanças climáticas causadas pelas variações periódicas da órbita da Terra ao redor do Sol. (Penck 1914; Bradley 1929; Twenhofel 1932; Krynine 1942; Garner 1959; Van Houton 1964; Crook 1967; Young et al. 1975; Fairbridge 1976; Olsen 1980; LeTourneau 1985; Herbert and Fischer 1986; Dean and Gardner 1986; Perlmutter and Matthews 1989).

Os ciclos climáticos, induzidos orbitalmente, podem gerar ciclos sedimentares tendo como principais fenômenos os seguintes: 1- variações do nível do mar devido à variação do volume do gelo nas geleiras em grandes altitudes; 2- variações no nível dos lagos devido a variações regionais no balanço hídrico (evaporação/precipitação) da região; 3- mudanças nas taxas de produção, tamanho de grãos, mineralogia, intemperismo e bacia de drenagem; 4- mudanças nas taxas de transporte através da alteração das condições hidrodinâmicas dos sistemas fluviais; e 5 - mudanças nos ambientes deposicionais, devido à alteração do clima na bacia receptora dos sedimentos.

Azambuja Filho (1990), um dos pioneiros no desenvolvimento desses estudos no Brasil, identificou ciclos carbonáticos em sedimentos oligocênicos da Bacia de Campos modulados por oscilações climáticas, principalmente relacionadas a movimentos de precessão e de excentricidade, tornando possível o refinamento do arcabouço estratigráfico existente em pelo menos uma ordem de grandeza. Assim, com a utilização da cicloestratigrafia, o arcabouço bioestratigráfico existente baseado em nanofósseis calcários, que tinha uma resolução entre $1.800 \mathrm{Ka}$ a $4.000 \mathrm{Ka}$, foi refinado para alguns milhares de anos através da identificação dos ciclos de $100 \mathrm{Ka}$ e de $20 \mathrm{Ka}$. Maiores detalhes do estudo serão apresentados na parte II desta publicação.

O refinamento cicloestratigráfico de seções sedimentares, além de fornecer um ótimo arcabouço para interpretações, permite o desenvolvimento da Estratigrafia Sintética e da Modelagem Sedimentar, pois para executar simulações numéricas precisas é necessário quantificar taxas de sedimentação para curtos intervalos de tempo. A interação da Cicloestratigrafia com a Estratigrafia Sintética mostra-se assim como uma área promissora que se descortina na pesquisa estratigráfica sedimentar. E cada vez mais será necessário desenvolver técnicas que possam aumentar a resolução dos métodos convencionais.

Oscilaçães orbitais de Milankovitch: o núcleo dos ciclos climáticos Ciclos climáticos são produzidos pela interação dos parâmetros orbitais da Terra, excentricidade, obliqüidade e precessão dos equinócios, os quais periodicamente alteram o grau de insolação sazonal que a Terra recebe (Milankovitch 1941; Berger 1980; Lockwood 1980; Fischer 1986; Kukla and Gavin 1992; Perlmutter and Plotnick, 2002; De Boer \& Smith 1994a). A excentricidade causa uma variação na órbita da Terra ao redor do Sol de elíptica para praticamente circular. Quando a órbita é elíptica, a distância da Terra ao sol varia ao longo de todo o ano (Figuras 1, 2 e 3). A precessão muda progressivamente quando ocorre da órbita da Terra estar mais próxima do sol (periélio) e mais distante (afélio). Em outras palavras, nos períodos do ano quando ocorre o periélio e o afélio as mudanças ocorrem na precessão.

Atualmente a Terra fica mais próxima do Sol em Dezembro e mais longe em Junho. $O$ impacto da precessão na isolação terrestre diminui e desaparece quando a excentricidade está próxima de zero. Como resultado, a excentricidade agrupa ciclos de precessão através da redução parcial ou mesmo total das mudanças na insolação, causadas pela precessão, quando a órbita da Terra torna-se circular.

A obliqüidade causa sazonalidade devido à inclinação do eixo do pólo de rotação da Terra, de modo que quanto mais inclinado estiver o eixo maior será a sazonalidade. A obliqüi- 
dade também causa a defasagem das estações em seis meses nos hemisférios Norte e Sul. Quando é verão em um hemisfério no outro é inverno. Quando a excentricidade e a obliqüidade são combinadas elas causam um efeito de defasagem nos efeitos da precessão entre os hemisférios também. Por exemplo, quando o periélio ocorre durante o verão do Hemisfério Norte, ou seja, em Junho, o afélio ocorrerá seis meses mais tarde durante o verão no Hemisfério Sul, ou seja, em Dezembro (Figura 4). Este fato é importante para podermos entender porque, quando a órbita da Terra é excêntrica, ocorrem verões quentes (periélio no verão) em um hemisfério e invernos frios (afélio no inverno) no outro Hemisfério, enquanto que ao contrario ocorrem verões moderados (afélio no verão) e invernos moderados (periélio no inverno). Este padrão hemisférico inverte gradualmente dentro de um ciclo de precessão. O ciclo de obliqüidade pode se tornar dominante quando a excentricidade se aproxima de zero.

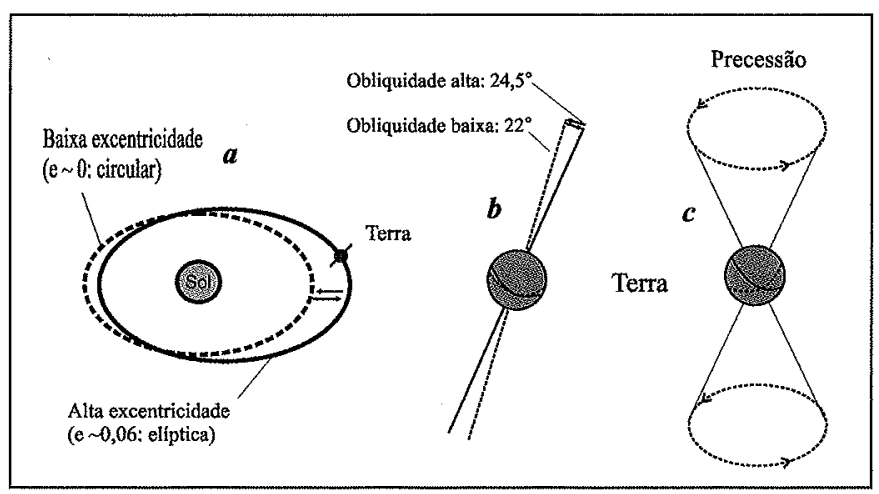

Figura 1 - Ciclos orbitais, ou de Milankovitch: (a) excentricidade; (b) obliqüidade; (c) precessão (Modificado de De Boer \& Smith 1994a).

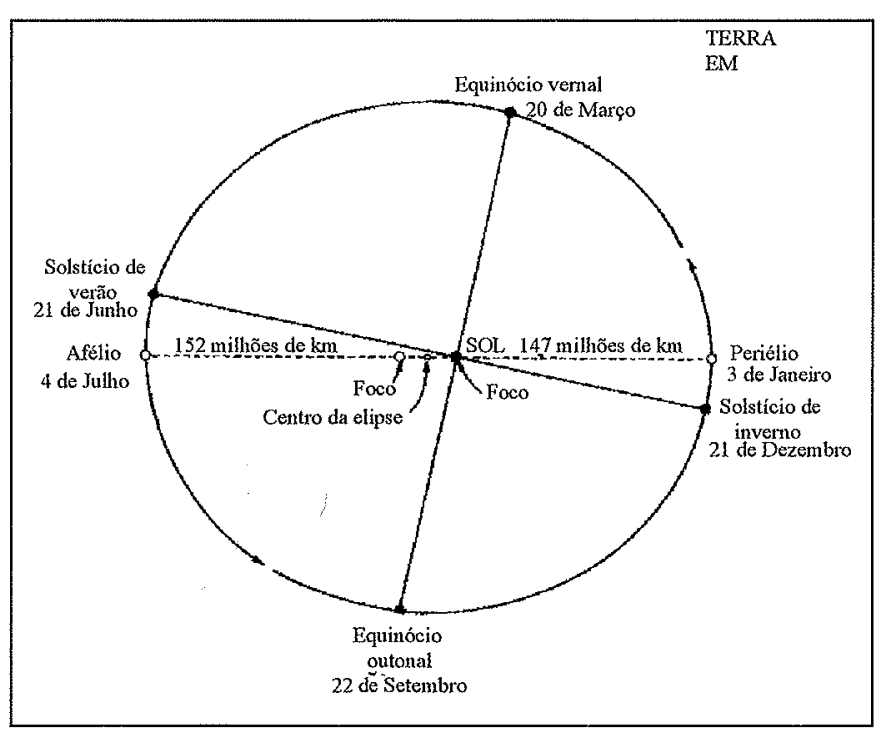

Figura 2 - Datas do equinócio e do solstício. No equinócio, o eixo da Terra está em ângulo reto em relação à eclíptica, o plano de deslocamento relativo do Sol em torno do planeta, $e$ o dia e a noite têm igual duração ao longo do globo. No solsticio de verão, o pólo norte está inclinado em direção ao Sol e o hemisfério norte tem o dia mais longo do ano. No solstício de inverno, o pólo norte está inclinado de maneira oposta ao Sol e o hemisfério norte tem o dia mais curto do ano (Modificado de Imbrie \& Imbrie 1979).

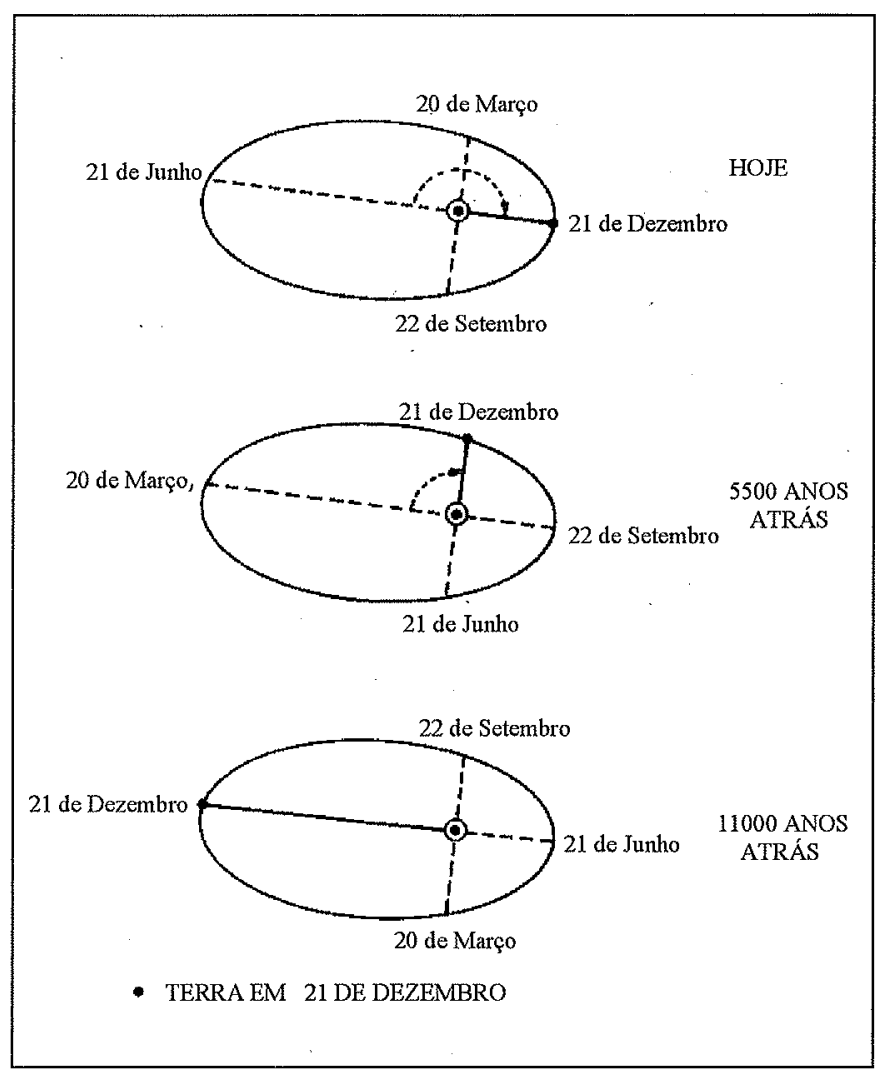

Figura 3 - Precessão dos equinócios. Devido à precessão do eixo e a outros movimentos astronômicos, as posições do equinócio e do solstício se deslocam lentamente ao longo da órbita elíptica da Terra e completam um ciclo inteiro a cada 22 mil anos aproximadamente. Há 11 mil anos, o solstício de inverno ocorreu próximo ao lado oposto da órbita em relação à sua ocorrência atual. Como resultado, a distância entre a Terra e o Sol, medida em 21 de dezembro, muda (Modificado de Imbrie \& Imbrie 1979).

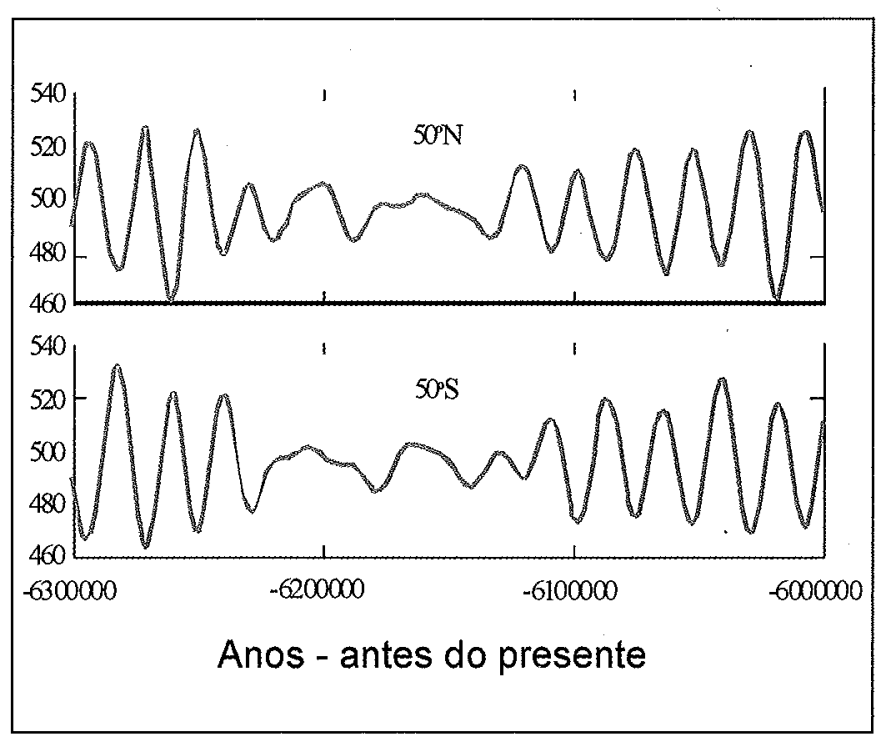

Figura 4 - Ciclos de insolação plotados $50^{\circ}$ Norte e Sul. Com base no cálculo de insolação obtido pelas equações de Berger (1978), a relação antípoda das fases na escala de precessão desaparece ou sofre uma leve inversão quando a excentricidade se aproxima de zero, aproximadamente entre os anos $615.000 \mathrm{e}$ 620.000 antes do presente. 
Os harmônicos primários dos ciclos de excentricidade têm períodos ao redor de $100 \mathrm{ka} \mathrm{e} 413 \mathrm{ka}$, precessão em torno de $19 \mathrm{ka}$ e 23 ka, e obliqüidade em torno de 41 ka, com base nos parâmetros orbitais atuais. Devido a efeitos construtivos ou destrutivos de interferência dessas freqüências primárias podem ser geradas variações de insolação de mais longo período em torno de 1,6 a 2,4 Ma (Matthews and Frohlich 1991). Equações para calcular ciclos orbitais para os últimos 10 milhões de anos foram desenvolvidas por Berger (1978) e Berger \& Loutre (1988). Quando os ciclos sazonais de insolação são plotados, fica visível que as maiores mudanças na insolação, cerca de 30\%, ocorre coincidentemente na escala da periodicidade da precessão (Figura 4). Apesar dessas equações serem especificamente para os últimos $10 \mathrm{Ma}$, as variações na insolação ocorreram ao longo de toda a história da Terra (Berger et al. 1992). É importante reconhecer, no entanto, que o período e a amplitude das freqüências dos ciclos de Milankovitch variaram gradualmente ao longo do tempo geológico, sendo a excentricidade curta a mais constante delas (Berger \& Loutre 1988).

Respostas climáticas aos ciclos orbitais Mudanças na sazonalidade da insolação podem alterar o padrão de temperatura regional. A atmosfera acomoda mudanças no aquecimento através do ajuste da distribuição das células de pressão atmosférica e dos padrões de circulação. Combinadas as mudanças de temperatura, pressão e circulação, alteram-se os padrões de precipitação e evaporação, mudando os padrões de climas associados gerando ciclos climáticos (Glennie 1984; Perlmutter \& Matthews 1989; Park \& Oglesby 1994; Perlmutter et al. 1998). A superposição e a interação dos ciclos orbitais cria um espectro repetitivo de climas na alta freqüência, limitados por máximos e mínimos com uma freqüência mais baixa. Esses máximos e mínimos climáticos indicarão os intervalos mais quentes e frios do planeta, e podem ser associados com períodos glaciais e inter-glaciais (Figura 5a). Os máximos e mínimos climáticos alongam ou encurtam as células de circulação (Hadley = tropical, Ferrel = temperada, e Polar), as quais definem padrões zonais de dinâmica atmosférica (Figura 5b). A partir disso podem ser cria- dos padrões climáticos atmosféricos zonais ou bandas climáticas, de acordo com a latitude geográfica que são influenciados por processos meridionais relacionados com a distribuição das terras, dos mares e da topografia (Perlmutter e Mathews, 1992; Perlmutter et al, 1998).

Simulações climáticas de alta freqüência do Cretáceo Médio (Park \& Oglesby 1994) e do presente (Moore et al., 2000) indicam que as maiores mudanças ocorridas em uma dada região estão associadas com mudanças que ocorrem na escala de precessão. Os ciclos de excentricidade e de obliqüidade modulam a extensão do efeito, assim como acontece com a interferência com os principais harmônicos das freqüências orbitais. O resultado é uma coleção repetitiva de curto período, ciclos climáti$\cos$ na escala de precessão, que variam entre as verdadeiras condições extremas determinadas pela interação da influência de longo período. O resultado é um conjunto repetitivo de ciclos climáticos de curta duração, na escala de precessão, que variam entre as verdadeiras condições extremas determinadas pela interação com os ciclos de longa duração. O membro extremo das condições mais quentes será chamado de máximo climático e o membro extremo das condições frias será chamado de mínimo climático. Contudo, a resposta do sistema climático de uma determinada região, a uma condição específica de insolação, não é apenas uma função da fase de insolação do ciclo. A resposta está ligada diretamente com a localização geográfica (latitude e longitude) e da geografia ou paleogeografia da área (Perlmutter \& Matthews 1989; Park \& Oglesby 1994; Perlmutter et al. 1995; Moore et al., 2000). Como resultado, em um determinado hemisfério nem todas as áreas tornam-se úmidas ou áridas para um mesmo ponto num ciclo de insolação. Por exemplo, à medida que a insolação varia em um ciclo orbital, áreas equatoriais podem tornar-se mais áridas, enquanto que áreas de latitudes médias tornam-se mais úmidas ou uma área de latitude média torna-se úmida enquanto outra se torna árida. A variabilidade climática é função de condições regionais específicas e que podem mudar ao longo do tempo geológico. Como conseqüência, diferentes zonas de um mesmo hemisfério podem ficar sujeitas a diferentes sucessões climáticas como resposta ao mesmo ciclo
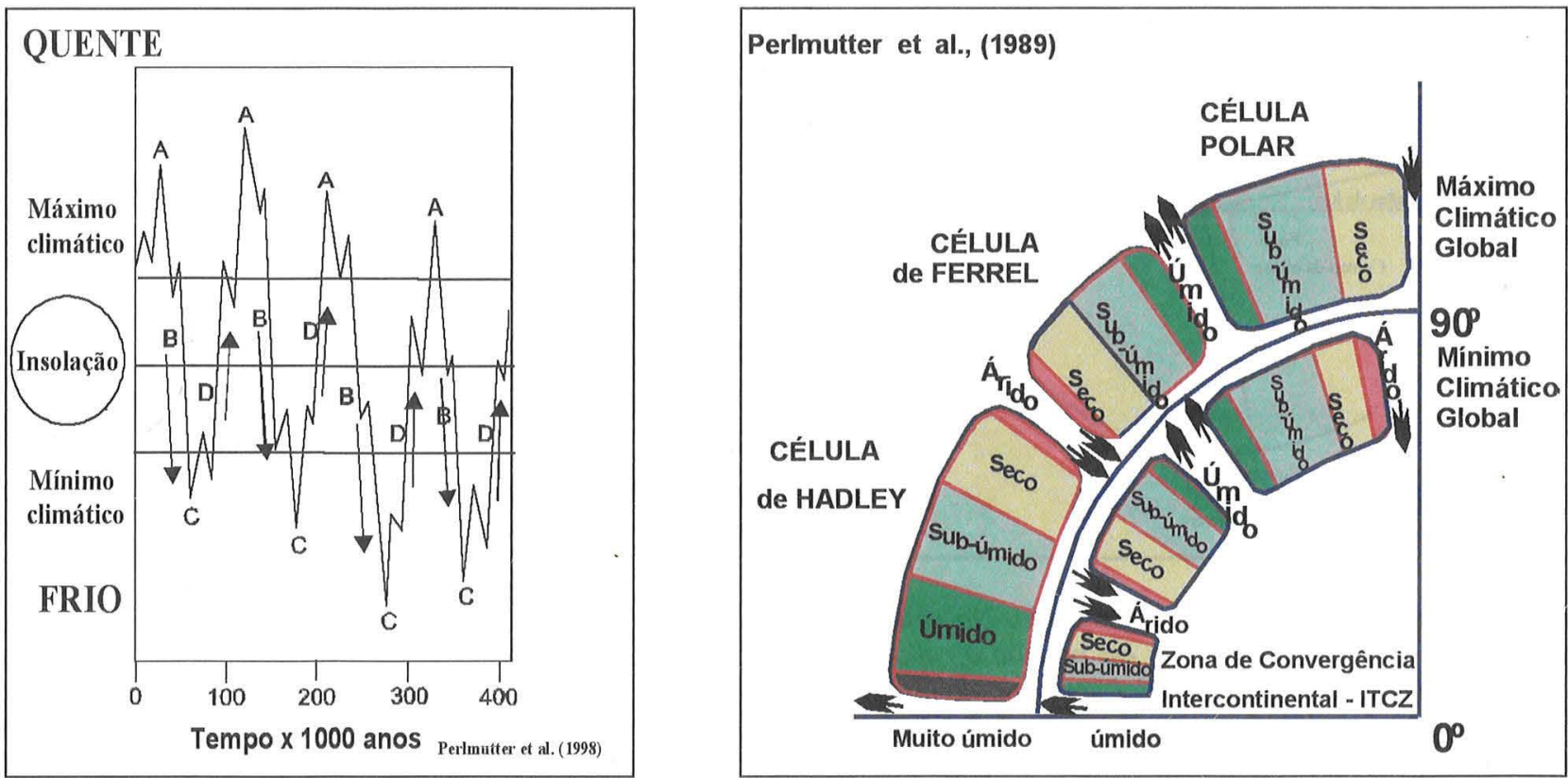

Figura 5 a - Máximos e mínimos climáticos causados pela interferência dos ciclos orbitais para os últimos 400 mil anos. Modificado de Perlmutter et al, 1998. Figura 5b-Definição dos cinturões de alta e baixa pressão gerados pelas células de circulação nas condições de máximo e mínimo climático. Modificado de Perlmutter e Mathews, 1989. 

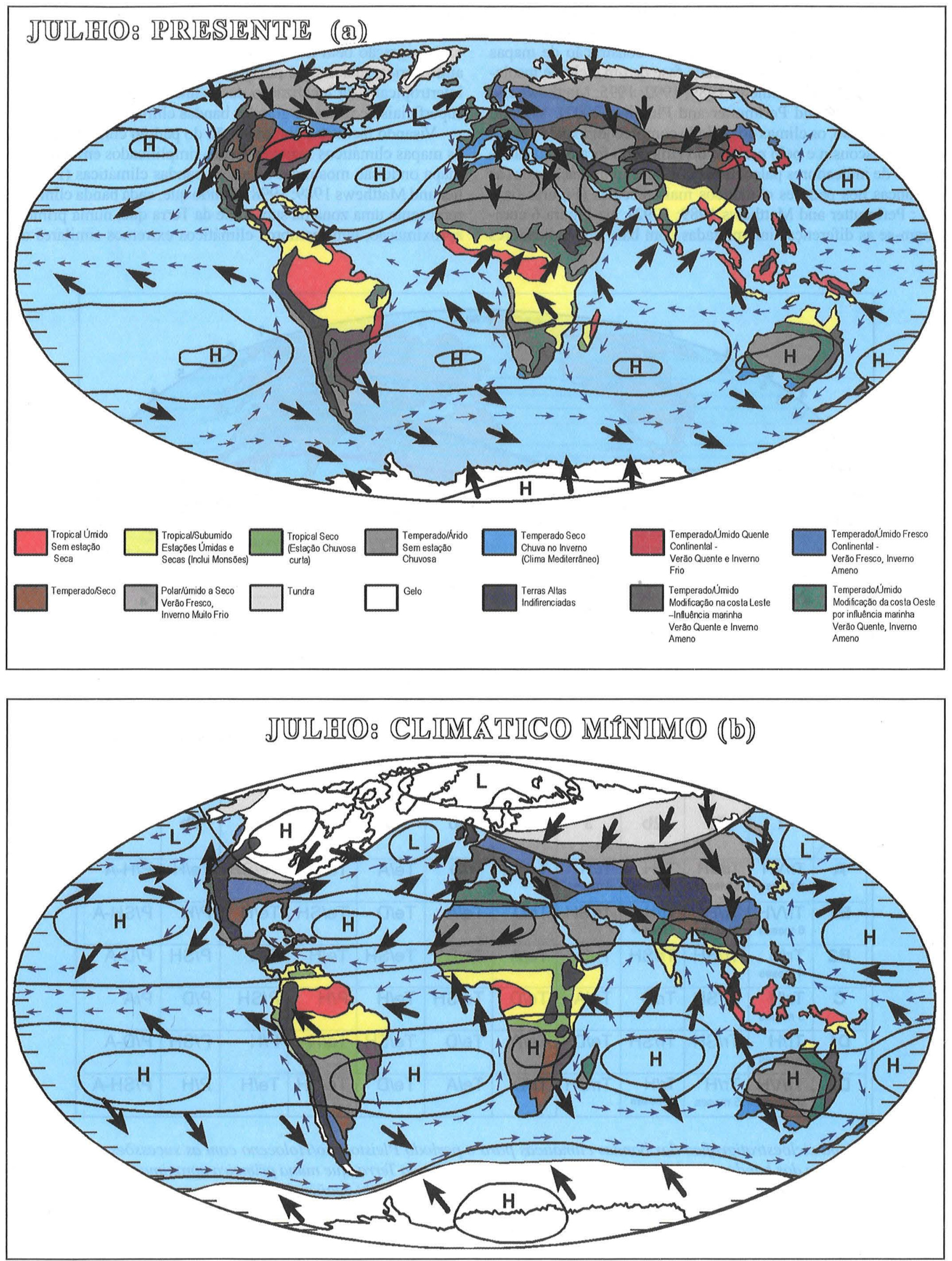

Figura 6 - Distribuição dos padrões climáticos globais com a posição média das células de pressão atmosférica para uma posição em julho, padrão de ventos e correntes oceânicas superimpostas. (a) Presente, (b) último mínimo climático estimado pelos indicadores paleoclimáticos (modificado de Perlmutter \& Matthews 1989). 
de insolação. Mudanças climáticas regionais podem ser interpretadas através do mapeamento da distribuição dos indicadores paleoclimáticos em escala global e pela construção de mapas de sazonalidade climática para cada fase de um ciclo de insolação (Perlmutter and Matthews 1989; 1992; 1995; Matthews and Perlmutter 1994 and Perlmutter and Plotnick, 2002). Visando demonstrar isso, os climas do período compreendido pela glaciação de Wisconsin e pelo período do Holoceno foram mapeados através de indicadores paleoclimáticos para comparação com as mudanças nos padrões climáticos mais recentes (Figuras 6a e 6b) ; Perlmutter and Matthews 1989; 1992). Na Figura 6 comparam-se as diferenças interpretadas com base nos indicadores paleoclimáticos para o último período climático mínimo com as condições atuais durante o mês de julho. Observe que existe uma migração bem definida em direção ao pólo na circulação atmosférica, incluindo a posição de uma zona de convergência intertropical e da localização das células de pressão, correntes superficiais oceânicas e grandes bandas climáticas.

Visando facilitar a compreensão do padrão climático global, os mapas climáticos sazonais foram simplificados em um único mapa onde são mostradas séries de bandas climáticas (Perlmutter and Matthews 1989; 1998). Sendo que, cada banda climática representa uma zona da superfície da Terra que, numa primeira aproximação, tem membros climáticos extremos similares du-

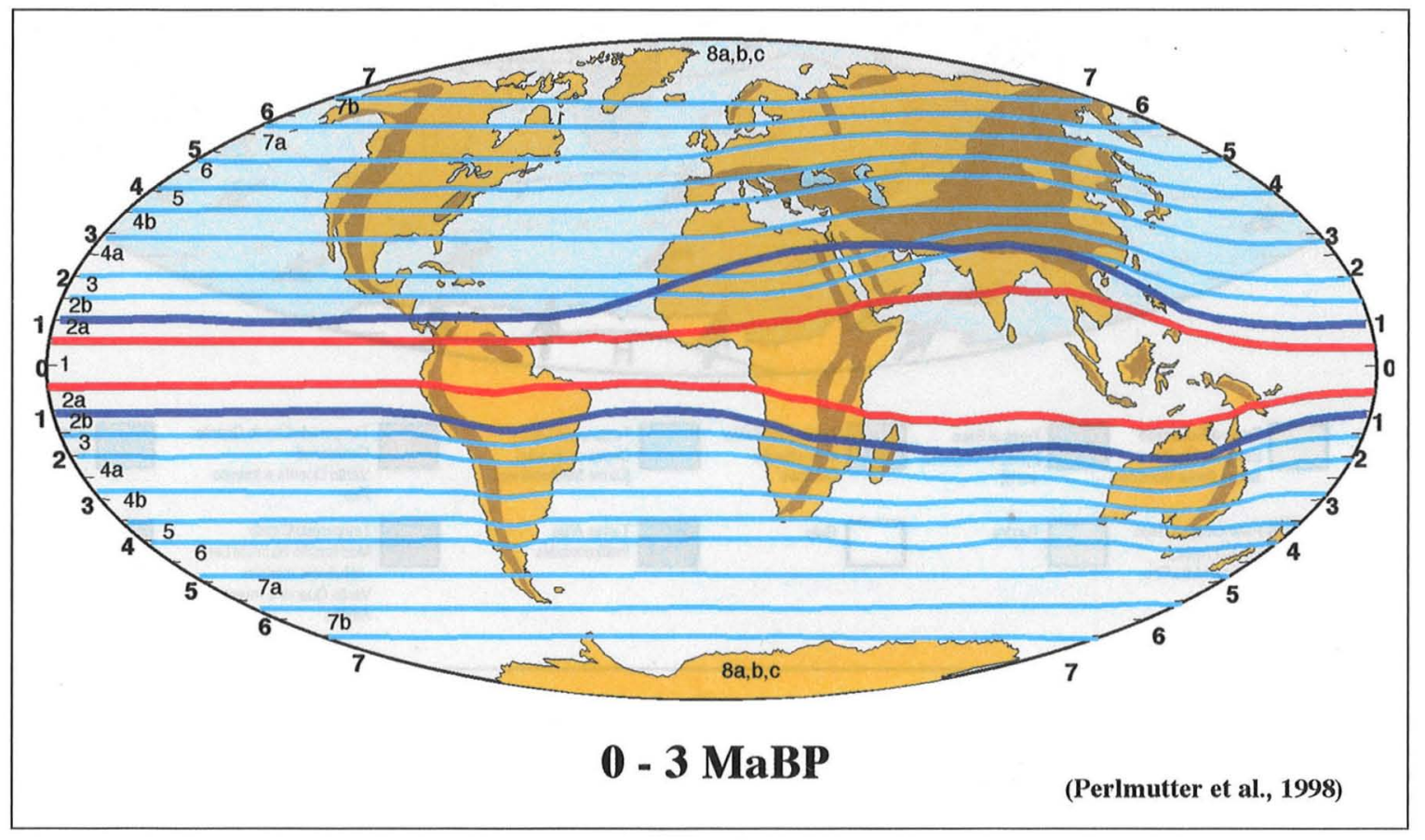

\begin{tabular}{|c|c|c|c|c|c|c|c|c|c|c|c|}
\hline Banda & 1 & $2 a$ & $2 b$ & 3 & $4 a$ & $4 b$ & 5 & 6 & $7 a$ & $7 b$ & 8 \\
\hline A & $\begin{array}{l}\text { Tr/VH } \\
6 \text { meses }\end{array}$ & $\begin{array}{l}\text { Tr/VH } \\
6 \text { meses }\end{array}$ & $\begin{array}{l}\text { Tr/H } \\
5 \text { meses }\end{array}$ & $\begin{array}{l}\mathrm{Tr} / \mathrm{H} \\
4 \mathrm{meses}\end{array}$ & $\mathrm{Tr} / \mathrm{SH}$ & $\mathrm{Tr} / \mathrm{D}$ & Te/A & $\mathrm{Te} / \mathrm{D}$ & $\mathrm{Te} / \mathrm{SH}$ & $\mathrm{Te} / \mathrm{H}$ & $\mathrm{P} / \mathrm{H}-\mathrm{A}$ \\
\hline B1 & $\begin{array}{l}\mathrm{Tr} / \mathrm{VH} \\
6 \text { meses }\end{array}$ & $\begin{array}{l}\mathrm{Tr} / \mathrm{H} \\
5 \text { meses }\end{array}$ & $\begin{array}{l}\mathrm{Tr} / \mathrm{H} \\
4 \mathrm{meses}\end{array}$ & $\mathrm{Tr} / \mathrm{SH}$ & $\mathrm{Tr} / \mathrm{D}$ & TelA & $\mathrm{Te} / \mathrm{D}$ & $\mathrm{Te} / \mathrm{SH}$ & $\mathrm{Te} / \mathrm{H}$ & $\mathrm{P} / \mathrm{H}$ & $\mathrm{P} / \mathrm{SH}-\mathrm{A}$ \\
\hline B2 & $\begin{array}{l}\mathrm{Tr} / \mathrm{H} \\
4 \text { meses }\end{array}$ & $\mathrm{Tr} / \mathrm{SH}$ & $\mathrm{Tr} / \mathrm{SH}$ & Tr/D & Te/A & $\mathrm{Te} / \mathrm{D}$ & $\mathrm{Te} / \mathrm{SH}$ & $\mathrm{Te} / \mathrm{H}$ & $\mathrm{P} / \mathrm{H}$ & $\mathrm{P} / \mathrm{SH}$ & P/D-A \\
\hline C & $\begin{array}{l}\mathrm{Tr} / \mathrm{H} \\
3 \text { meses }\end{array}$ & $\mathrm{Tr} / \mathrm{SH}$ & $\mathrm{Tr} / \mathrm{D}$ & TelA & $\mathrm{Te} / \mathrm{D}$ & $\mathrm{Te} / \mathrm{SH}$ & $\mathrm{Te} / \mathrm{H}$ & $\mathrm{P} / \mathrm{H}$ & $\mathrm{P} / \mathrm{SH}$ & P/D & $\mathrm{P} / \mathrm{A}$ \\
\hline D1 & $\begin{array}{l}\mathrm{Tr} / \mathrm{H} \\
4 \mathrm{meses}\end{array}$ & $\mathrm{Tr} / \mathrm{SH}$ & $\mathrm{Tr} / \mathrm{SH}$ & Te/D & $\mathrm{Te} / \mathrm{A}$ & $\mathrm{Te} / \mathrm{D}$ & $\mathrm{Te} / \mathrm{SH}$ & $\mathrm{Te} / \mathrm{H}$ & $\mathrm{P} / \mathrm{H}$ & $\mathrm{P} / \mathrm{SH}$ & P/D-A \\
\hline D2 & $\begin{array}{l}\text { Tr/NH } \\
5 \text { meses }\end{array}$ & $\begin{array}{l}\mathrm{Tr} / \mathrm{H} \\
5 \mathrm{meses}\end{array}$ & $\begin{array}{l}\mathrm{Tr} / \mathrm{H} \\
4 \mathrm{meses}\end{array}$ & $\mathrm{Tr} / \mathrm{SH}$ & Tr/D & Te/A & $\mathrm{Te} / \mathrm{D}$ & $\mathrm{Te} / \mathrm{SH}$ & $\mathrm{Te} / \mathrm{H}$ & $\mathrm{P} / \mathrm{H}$ & P/SH-A \\
\hline
\end{tabular}

Figura 7 - Mapa cicloestratigráfico das bandas climáticas para o periodo Pleistoceno/Holoceno com as sucessões climáticas associadas. (a) Mapa das bandas climáticas mostrando áreas da superficie da Terra, que numa primeira aproximação, possuem similares mudanças (Perlmutter \& Matthews 1989; Matthews \& Perlmutter 1994). (b) Seqüências climáticas e seus membros extremos, idealizados, por bandas cicloestratigráficas para o Pleistoceno/Holoceno. O ciclo climático é dividido em seis fases: A - máximo climático, B1 e B2 - transição de resfriamento, C-mínimo climático, e D1 e D2 - transição de aquecimento (vide figura $5 a$ ). As dimensões uniformes dos quadros não indicam necessariamente que cada fase tenha a mesma duração temporal. Áreas equatoriais são afetadas por monções úmidas durante algumas fases climáticas, com um numero de meses chuvosos indicados entre parêntesis. Observe que se torna mais úmido nas latitudes médias em direção ao mínimo climático, enquanto as regiões equatoriais e polares ficam mais secas. Abreviações: $T r=$ tropical; Te =temperado; $P=$ polar $; H H=$ muito úmido; $H=$ úmido; $S H-$ subúmido; $D=$ seco; $A$ = árido. Veja testo para maiores explicações. 


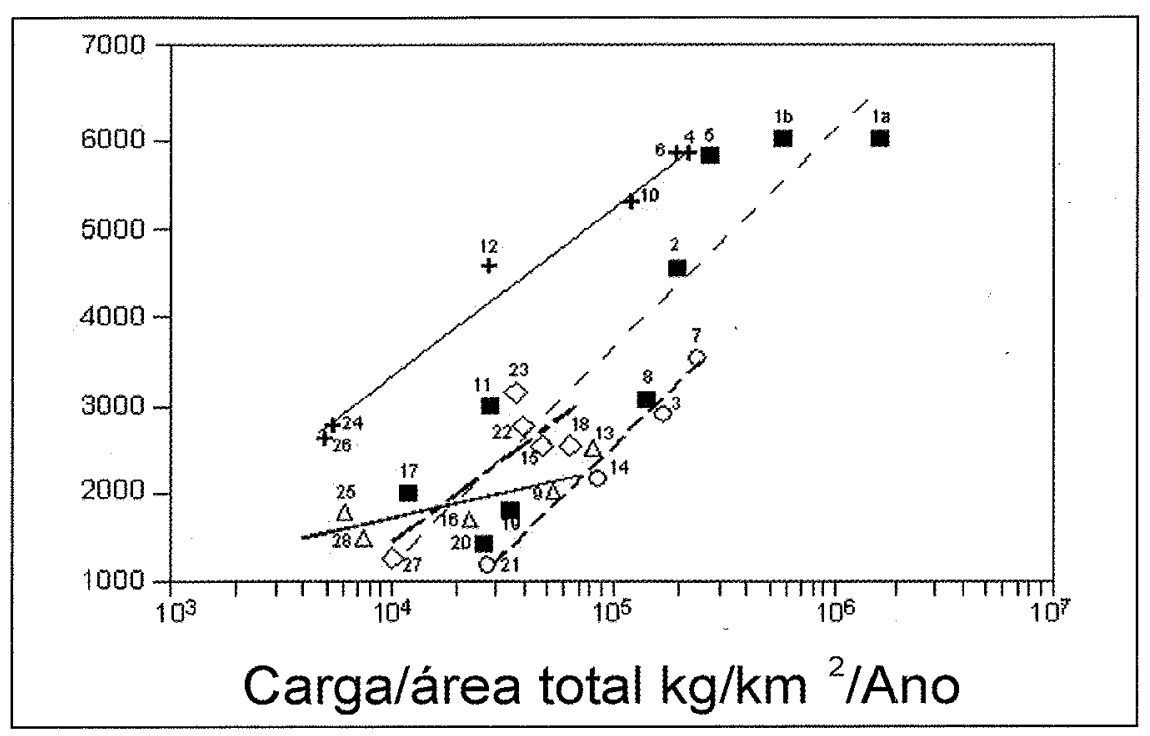

Figura 8 - Produção de sedimentos por unidade de área versus elevação topográfica dividido por clima (Perlmutter et al. 1998). Os números representam os sistemas fluviais estudados: (la) Brahamaputra, (1b) Ganges, (2) Amazonas, (3) Mississippi, (4) Chiang Jiang, (5) Indus, (6) Mekong, (7) Colorado, (8) Orinoco, (9) MacKenzie, (10) Huang He, (11) Nilo, (12) La Plata, (13) Yukon, (14) Danúbio, (15) Orange, (16) Amur, (17) Zaire, (18) Shatt-El-Arab, (19) Zambezi, (20) Niger, (21) Murray, (22) Columbia, (23) Rio Grande, (24) Ob, (25) Lena, (26) Yenisei, (27) São Francisco, e (28) Kolyma. A estimativa de produção de sedimentos para as áreas fontes com o clima foram estimados através de valores médios.

rante o período de um ciclo. A sucessão climática de uma banda é feita através da interpolação entre os membros extremos. Contudo, para utilizarmos o mapa de bandas climáticas para avaliar a variação de uma determinada área, devem ser incorporadas na interpretação as condições que podem modificar essas características climáticas, desde a escala regional até a local. As condições que devem ser levadas em consideração são os ventos predominantes, a proximidade de um oceano ou de um grande corpo de água, a temperatura do oceano e das correntes, efeitos orográficos e de monções. O Mapa das bandas climáticas para os últimos três milhões de anos pode ser visto na Figura 7. A sucessão climática de cada banda climática, por fase do ciclo de insolação, é mostrada na Figura 7. De um modo geral, as regiões equatoriais e polares tendem a tornarem-se mais secas e as regiões de latitude média tendem a tornarem-se mais úmidas à medida que ocorre a progressão do máximo para o mínimo climático. Contudo, mesmo nesta visão simplificada da mudança do clima durante um ciclo de insolação, está claro um padrão altamente variável.

Um nível adicional de complexidade é adicionado quando se considera que os ciclos de insolação dos hemisférios Norte e Sul estão defasados de $180^{\circ}$ na escala de precessão (Perlmutter et al. 1998; Perlmutter and Plotnick, 2002). Isto causa uma defasagem de aproximadamente $10 \mathrm{ka}$ nas mesmas sucessões climáticas nos hemisférios opostos. Para ilustrar, a insolação de verão mais forte para um hemisfério, o máximo climático, ocorre quando a excentricidade é alta e o periélio ocorre durante o verão (Kukla and Gavin 1992). O afélio irá ocorrer durante o inverno, seis meses depois. A condição de insolação fraca de inverno, o mínimo climático, ocorre quando a excentricidade é alta e o afélio ocorre durante o verão, e o periélio ocorre durante o inverno subseqüente. Como conseqüência, verões quentes e invernos frios caracterizam o máximo climático hemisférico, enquanto verões frescos $\mathrm{e}$ invernos amenos caracterizam o mínimo climático hemisférico. $\mathrm{Na}$ escala de precessão, temse como resultado, de um modo geral, o máximo climático no Hemisfério Norte enquanto no Sul tem-se o mínimo climático. Uma das conseqüências dessa defasagem hemisférica poderia ser a capacidade das monções produzirem chuva no verão. Os climas de monções tendem a responder diretamente à insolação e são mais fortes quando os valores de insolação hemisférica são maiores (Kerr 1986; Park \& Oglesby 1994). Então, a rigor, monções chuvosas podem existir num hemisfério, enquanto uma monção seca e fraca ocorre no outro hemisfério, por causa das diferenças no aquecimento no verão, mesmo que as condições geográficas fossem idênticas (latitude, área terrestre, proximidade do oceano, temperatura da superfície do mar, topografia e direções predominantes de ventos, etc.). Essas variações requerem uma avaliação paleoclimática para um período específico de tempo, abrangendo pelo menos quatro mapas sazonais, e incluído julho e janeiro para o máximo e mínimo climático, que são os responsáveis pela variação dos indicadores climáticos em um intervalo (Perlmutter et al. 1995; 1998). Quando as áreas equatoriais estão sendo avaliadas, um mapa de equinócio também é interpretado para as condições de máximo e mínimo climático.

Relação do clima com o nível do mar Como visto acima, a resposta climática a um ciclo de insolação específico é de caráter regional. Ou seja, nem todas as regiões ficam quentes ou frias, úmidas ou secas, ao mesmo tempo, em um determinado ponto geográfico de um ciclo de insolação. Contudo, a resposta glacioeustática a um determinado ciclo de insolação é global, com sincronismo dos níveis altos e baixos do mar na Terra, em função da conexão dos oceanos. Isto implica em que ciclos climáticos regionais de diferentes áreas podem ter diferentes relações com os ciclos glacioeustáticos (Perlmutter et al. 1995; 1998; Perlmutter \& Plotnick, 2002; 2003). Como o clima regional impacta diretamente o intemperismo, o transporte de sedimentos e os ambientes deposicionais, essas diferenças de fase entre os ciclos climáticos regionais e os ciclos de variação do nível do mar global podem produzir padrões estratigráficos muito diferentes durante o mesmo ciclo de insolação. É extremamente importante ter consciência de que um ciclo de insolação pode causar a variação de ciclos estratigráficos, a depender de condições climática e de deposição especificas para 


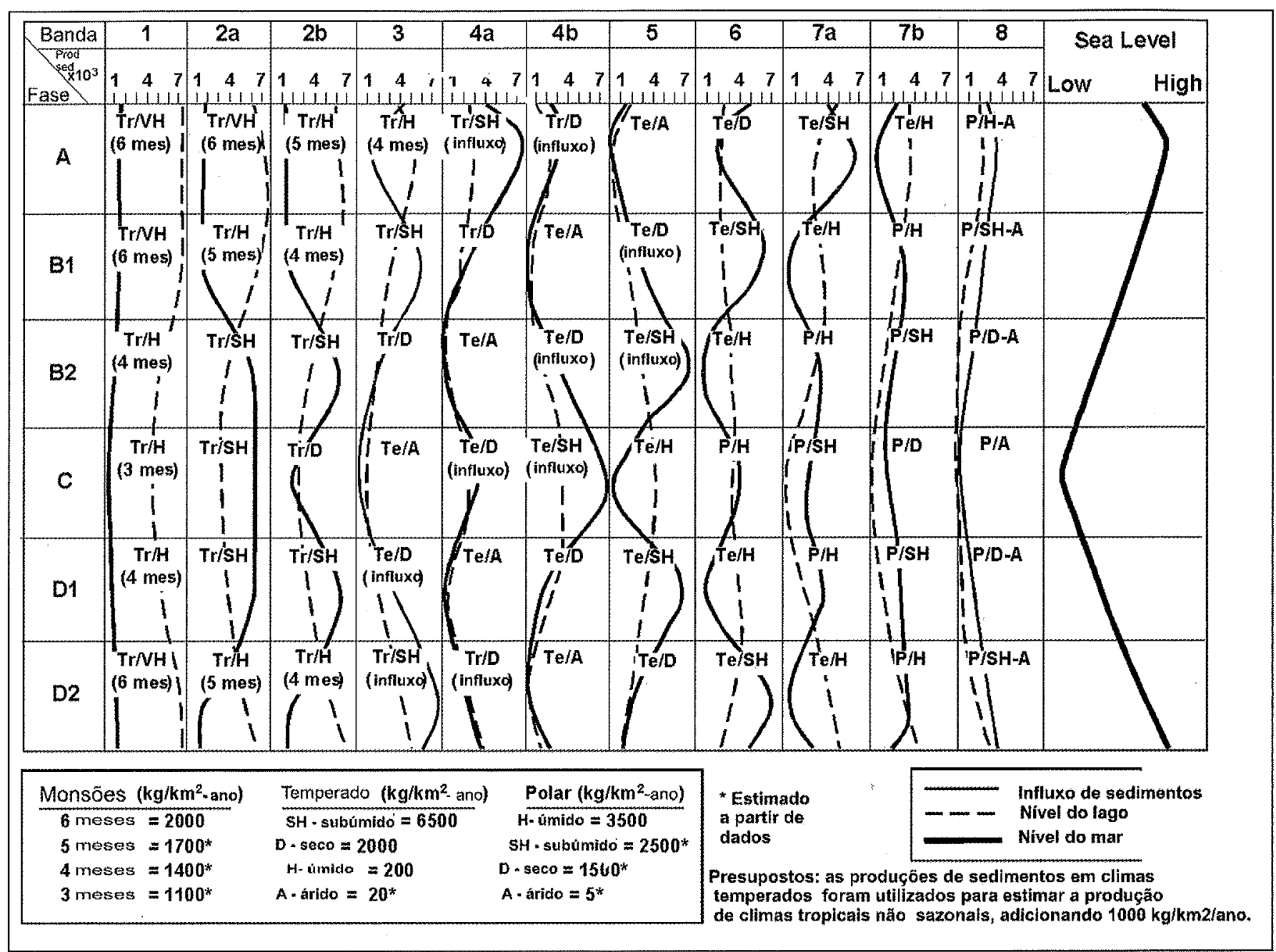

Figura 9 - Produção sedimentar para cada banda cicloestratigráfica por fase climática, nivel do mar, e nível de lago (Perlmutter et al. 1998). As curvas contínuas representam a produção de sedimento e as tracejadas o nível de lago; o nível do mar é mostrado à direita. Estimativas dos dados estão indicadas em asteriscos. Abreviações: $T r=$ tropical; $T e=$ temperado; $P=$ polar; VH=muito úmido; $H=$ úmido; $S H$-subúmido; $D=$ seco; $A=$ árido. Veja o texto para as explicações.

um determinado local na correlação estratigráfica e na elaboração de arcabouços geocronológicos. Para podermos avaliar esse fenômeno inteiramente é necessário avaliarmos o impacto do clima e da sedimentação.

O IMPACTO DO CLIMA NA PRODUÇÃO DE SEDIMENTOS Como indicado acima, as fases reais dos ciclos climáticos variam significativamente a depender da localização. Visando demonstrar como uma sucessão climática pode afetar o influxo sedimentar, ciclos de produção de sedimentos foram estimados para cada banda cicloestratigráfica, assumindo áreas de proveniência similares e uma elevação máxima de $2 \mathrm{~km}$ (Figura 9). Para essas análises, a maior mudança na produção de sedimentos ocorre numa sucessão climática que varia de árido para semi-úmido. Essa variação climática ocorre em latitude média nas bandas 3,4 a e 5 . A Figura 9 ressalta o fato de que os ciclos de produção sedimentar não são globalmente síncronos. Por exemplo, na banda 1 , a produção sedimentar é maior no máximo climático e menor no mínimo climático; na banda $4 \mathrm{~b}$, a produção sedimentar é maior no mínimo climático e menor nas transições climáticas, justamente antes e depois do máximo climático. Em geral, as bandas mostram mais de um episódio de pico de produção sedimentar em um ciclo climático. Como conseqüência, ciclos de sedimentação, produzidos por bacias fluviais em diferentes partes do mundo, não tem que estar em fase entre si ou em relação ao nível do mar.

Efeitos da interação do clima, sedimento e nível do mar As convenções utilizadas na terminologia de estratigrafia de seqüências assumem que: (1) à medida que o nível do mar ou do lago desce, a queda do nível de base a ele associado aumenta a produção de sedimentos por incremento da erosão dos vales dos rios a da recente plataforma exposta; e (2) durante a subida do nível do mar ou do lago, a associada subida do nível de base aprisiona sedimentos na bacia de drenagem fluvial a nas áreas recém inundadas, diminuindo a produção de sedimento para as áreas distais da bacia deposicional. Está claramente entendido que esta convenção deve ser alterada pelas considerações climáticas (Vail et al. 1977). A Figura 9 indica que somente nas sucessões climáticas representadas pelas bandas climáticas $2 \mathrm{a}$, $4 \mathrm{~b}$ e 5 a produção de sedimentos pode realmente aumentar, em dado ponto durante a queda do nível do mar, e diminuir durante a subida do nível do mar. Outras bandas mostram que o máximo suprimento de sedimento ocorre durante a subida do nível do mar, níveis de mar baixos ou altos, a depender da localização do ponto. Com vistas a investigar os efeitos potenciais do clima e do ciclo sedimentar na estratigrafia, Perlmutter et al. (1998) simularam quatro diferentes relacionamentos de fase 
Tabela 1 - O efeito da interação dos ciclos sedimentares e glacioeustáticos na interpretação de superficies estratigráficas chave e estratos especificos (Perlmutter et al. 1998).

\begin{tabular}{|c|c|c|c|c|c|}
\hline$\stackrel{\text { Superficies }}{\longrightarrow}$ & \multirow[t]{2}{*}{$\begin{array}{l}\text { Limite de } \\
\text { Sequência }\end{array}$} & \multirow[t]{2}{*}{$\begin{array}{c}\text { Superffcie } \\
\text { Transgressiva }\end{array}$} & \multirow{2}{*}{$\begin{array}{l}\text { Superficie } \\
\text { Máxima } \\
\text { inundação }\end{array}$} & \multirow[t]{2}{*}{$\begin{array}{c}\text { Seçāo } \\
\text { Condensada }\end{array}$} & \multirow{2}{*}{$\begin{array}{l}\text { Complexo } \\
\text { Progradacional } \\
\text { de mar baixo }\end{array}$} \\
\hline $\begin{array}{c}\text { Defasagem } \\
\mathbb{L}\end{array}$ & & & & & \\
\hline $\begin{array}{c}90^{\circ} \\
\text { (queda) }\end{array}$ & $\begin{array}{l}\text { Meioda } \\
\text { queda, } \\
\text { anterior ao } \\
\text { ponto de } \\
\text { intlexấo }\end{array}$ & $\begin{array}{l}\text { Inicio da } \\
\text { subida, logo } \\
\text { aposs o mar } \\
\text { baixo }\end{array}$ & $\begin{array}{l}\text { Final da } \\
\text { subida, } \\
\text { anterior ao } \\
\text { mar alto }\end{array}$ & $\begin{array}{l}\text { Subida do } \\
\text { nivel do mar }\end{array}$ & $\begin{array}{l}\text { Final da quedae } \\
\text { mar baixo }\end{array}$ \\
\hline $\begin{array}{c}180^{\circ} \\
\text { (baixo) }\end{array}$ & $\begin{array}{l}\text { Inicio da } \\
\text { queda, logo } \\
\text { após o mar } \\
\text { alto }\end{array}$ & $\begin{array}{l}\text { Inicio da } \\
\text { subida }\end{array}$ & Mar alto & Mar alto & $\begin{array}{c}\text { Mar baixo e } \\
\text { inicio da subida }\end{array}$ \\
\hline $\begin{array}{c}270^{\circ} \\
\text { (subida) }\end{array}$ & Mar baixo & $\begin{array}{l}\text { Metade da } \\
\text { subida, no } \\
\text { ponto de } \\
\text { inllexão }\end{array}$ & $\begin{array}{c}\text { Final da } \\
\text { subida, } \\
\text { mas } \\
\text { anterior ao } \\
\text { mar alto }\end{array}$ & $\begin{array}{l}\text { Queda do } \\
\text { nível do mas }\end{array}$ & $\begin{array}{l}\text { Metade da } \\
\text { subida }\end{array}$ \\
\hline $\begin{array}{l}360^{\circ} \\
\text { (alto) }\end{array}$ & $\begin{array}{c}\text { Inicio da } \\
\text { queda, entre } \\
\text { mar alto co } \\
\text { ponto de } \\
\text { inflexấo }\end{array}$ & Mar baixo & $\begin{array}{l}\text { Final da } \\
\text { subida, } \\
\text { entrc } \\
\text { ponto de } \\
\text { inflexão e } \\
\text { o mar alto }\end{array}$ & Mar baixo & $\begin{array}{l}\text { Final da queda } \\
\text { do nivel do mar }\end{array}$ \\
\hline
\end{tabular}

entre a produção de sedimentos e a eustasia utilizando o simulador numérico sedimentar 2D SEDPAK (Kendall et al. 1991). A produção sedimentar e os ciclos de variação do nível do mar foram simulados como simples curvas senoidais. As condições de fase que foram simuladas neste experimento foram: (1) máximo de produção durante a queda do nível do mar e mínimo durante a subida; (2) máximo de produção durante o trato de mar baixo e mínimo durante o trato de mar alto; (3) máxima produção durante a subida e mínimo durante a descida do nível do mar; e (4) máxima produção durante o trato de mar alto e mínimo durante o trato de mar baixo. Os resultados das simulações foram então interpretadas utilizando o arcabouço teórico da estratigrafia de seqüências como estabelecido por Vail et al. 1991. Os modelos de entrada e saída e as interpretações das superfícies estratigráficas foram comparados para a determinação os possíveis efeitos. Os resultados das comparações estão mostrados na Tabela 1. Mesmo utilizando condições simplificadas dos modelos, as variações são evidentes nas superfícies de tempo e nos tratos de sistemas relativos a cada ciclo eustático. Esta é uma informação importante, pois muitos intérpretes assumem que especificas superfícies estratigráficas e tratos de sistemas estão associados com certas fases do nível do mar. Este conjunto de experimentos sugere que os relacionamentos de fase de ciclos de sedimentação de alta frequiência podem impactar o tempo relativo do nível do mar através do retardo ou aceleração das condições que produzem superfícies regressivas ou transgressivas, aumentando ou inibindo o desenvolvimento de tratos de sistema. Perlmutter (1985) e Kolla \& Perlmutter (1993) demonstraram esse fenômeno através da reavaliação da estratigrafia do Pleistoceno do Golfo do México em relação ao ciclo de produção de sedimentos do rio Mississippi. Eles mostraram que a deposição dos leques submarinos se estende até a metade da subida do nível do mar durante a deposição do trato de sistema transgressivo. O relacionamento da fase pode também ser crítico quando uma superfície especifica é utilizada para correlação através de uma bacia ou entre bacias que foram preenchidas por múltiplos sistemas fluviais e que drenaram regiões com diferentes climas. O mesmo tipo de superficie em diferentes posições da bacia pode realmente representar diferentes fases da curva eustática. Os efeitos do relacionamento das fases de alta frequiência, dos ciclos de suprimento sedimentar

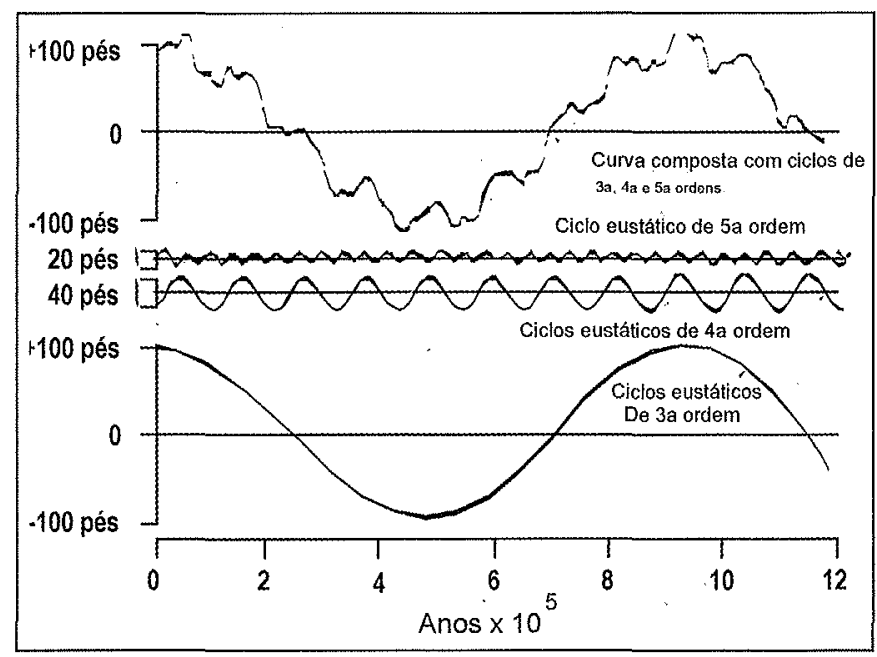

Figura 10 - Modelo de uma curva composta de variação do nivel do mar visando a geração de paraseqüências utilizando diferentes freqüencias e subsidência constante na bacia (modificado de Mitchum e Van Wagoner 1991). Este modelo é discutido no texto.

e dos ciclos de variação do nível de lagos em um ambiente deposicional lacustrino, podem ser ainda mais intensos do que nos ambientes marinhos. Visto que, os lagos e suas bacias de drenagem podem reagir mais rapidamente e com maior intensidade a uma mudança climática regional (Perlmutter and Matthews 1989, Matthews and Perlmutter 1994).

A tabela 1 foi compilada de interpretações de resultados de uma modelagem numérica 2D do software Sedpak. Uma mudança de fase em $90^{\circ}$ (queda) indica que a máxima amplitude do ciclo de suprimento sedimentar coincide com um rebaixamento do nível do mar. Uma mudança de fase de $180^{\circ}$ (baixo) indica o máximo de amplitude do ciclo de suprimento sedimentar coincide com o nível de mar baixo. Uma mudança de fase do ciclo de suprimento sedimentar de $270^{\circ}$ (subida) indica que a máxima amplitude do ciclo de suprimento sedimentar coincide com uma transgressão da linha de costa. Uma mudança de fase do ciclo de suprimento sedimentar de $360^{\circ}$ (alto) indica que a máxima amplitude do ciclo de suprimento sedimentar coincide com o nível de mar alto. Em complemento com a mudança na taxa de suprimento sedimentar, o clima também afeta a hidrodinâmica dos rios, tamanho de grãos, vegetação, turbidez, e salinidade na região costeira e etc. Por exemplo, variações no intemperismo em um ciclo climático podem influenciar a razão arenito/folhelho (Perlmutter and Matthews 1989). Adicionalmente, para algumas sucessões climáticas, o percentual de areia aumenta à medida que o volume total de sedimento diminui. Então, para determinadas regiões, o melhor tempo como potencial de reservatório será uma função do balanço entre o volume total de material grosso e o percentual da fração grossa no sedimento. A razão arenito/folhelho também impacta o potencia de selo das seções, o que pode afetar diretamente a migração e o trapeamento dos hidrocarbonetos. Vegetação e descarga de água doce podem afetar o tipo e o conteúdo do material orgânico nas potenciais rochas geradoras.

Em resumo, ciclos de variação do nível do mar causados por mudanças nas massas de gelo glaciais nos pólos, tendem a seguir os ciclos de insolação (Matthews and Frohlich 1991; Kukla and Gavin 1992; Berger 1992): o nível do mar fica alto quando a insolação é máxima e baixo quando a insolação é mínima. Adicionalmente, a sucessão climática de cada banda relativa do ciclo de insolação é diferente, causando variações 
no relacionamento das fases de produção de sedimento em relação ao nível do mar. Dependendo da localização, o máximo e o mínimo de produção de sedimento pode ocorrer em qualquer fase de um ciclo glacioeustático. O mesmo é verdadeiro para a produção de sedimento e curvas do nível de lagos.

Como conseqüências dessas variações, o potencial de reservatórios, selos e rochas geradoras podem ser afetados: (1) pelo ciclo climático, produção de sedimento e variação do nível de base (mar ou lago); e (2) terem diferenças regionais previsíveis. Esta informação deveria ser incorporada a programas de exploração focados naquelas bacias e intervalos estratigráficos com maior possibilidades de ocorrência de hidrocarbonetos. Mais especificamente, isto pode ser utilizado para focar na avaliação de prospectos focando em intervalos com tratos de sistemas com maior probabilidade de ocorrência de reservatório, capeado por uma boa rocha selante e nas proximidades de uma rocha geradora.

\section{FREQÜÊNCIAS E AMPLITUDES NO REGISTRO SEDI- MENTAR E MODELOS ESTRATIGRÁFICOS}

O modelo de seqüências estratigráficas, proposto por Mitchum and Van Wagoner, (1991; Figura 10) utiliza a interação da eustasia e da subsidência para a formação de seqüências de terceira ordem e de seqüências de alta freqüência. Esse modelo erroneamente sugere que as amplitudes das altas freqüências são sempre menores do que as amplitudes dos ciclos de baixa freqüência. Contudo, existe uma vasta quantidade de dados obtidos de registros de isótopos de oxigênio, em carapaças de foraminíferos do Pleistoceno, indicando que variações de alta freqüência do nível do mar também podem ter grandes amplitudes (Imbrie and Imbrie 1979). Os dados indicam que: (1) nos últimos 2 milhões de anos, o nível do mar repetidamente subiu e desceu dezenas de metros na escala de ciclos com periodicidades da ordem de $20 \mathrm{ka}$ (ciclo de precessão); e (2) e a maior subida do nível, acima de cem metros, foi na realidade a mais rápida, e ocorreu durante a fase de aquecimento do ciclo de precessão associado com a mudança da era glacial para a interglacial. O que o registro sedimentar realmente mostra é que os ciclos de terceira ordem são compostos por grupos de ciclos de alta freqüência mais do que o resultado de um único fenômeno de baixa freqüência e grande amplitude. Contudo, devido à baixa resolução vertical do dado sísmico disponível para estudos, as mudanças no registro sedimentar são mais bem definidas como ciclos ou seqüências de terceira ordem.

SUMÁRIO E DISCUSSÕES Em resumo, ciclos de variação do nível do mar causados por mudanças nas massas de gelo glaciais nos pólos tendem a seguir os ciclos de insolação: o nível do mar fica alto quando a insolação é máxima e baixo quando a insolação é mínima. Adicionalmente, a sucessão climática de cada banda relativa do ciclo de insolação é diferente, causando variações no relacionamento das fases de produção de sedimento em relação ao nível do mar. Dependendo da localização, o máximo e o mínimo de produção de sedimento pode ocorrer em qualquer fase de um ciclo glacioeustático. $\mathrm{O}$ mesmo é verdadeiro para a produção de sedimento e curvas do nível de lagos. Ou seja, a sucessão climática é função da posição geográfica, em quanto a variação eustática é de caráter global e tende a seguir o curso de ciclo de insolação. A relação de fase entre o ciclo de produção de sedimento e a glacioeustasia varia como função da paleogeografia. Os máximos e mínimos de suprimento sedimentar não são necessariamente uma função de um estágio específico do nível do mar. Simulações, relativamente simples executadas com o simulador estratigráfico Sedpak, visando compreender o impacto do suprimento sedimentar em relação aos ciclos de variação do nível do mar ou de um lago demonstram que superfícies e tratos de sistemas podem ocorrer em tempos diferentes de um ciclo de variação eustática, quando comparado com os padrões previstos pelo modelo de estratigrafia de seqüências. Como conseqüuência, as interpretações de variações do nível eustático, com base na relação temporal relativa ao influxo sedimentar, podem induzir interpretações estratigráficas não verdadeiras.

A inclusão do impacto do clima nas interpretações estratigráficas poderá permitir previsões mais acuradas na ocorrência dos principais elementos do sistema petrolifero de uma determinada bacia. A interação da produção de sedimentos com os ciclos de variação do nível do mar podem produzir respostas diferentes nos hemisférios Sul e Norte, durante os períodos glaciais. Esse fenômeno requer que seja avaliada a relação de fase entre a produção de sedimento e os ciclos glaciais para determinar quais as condições mais prováveis da deposição relativa na bacia (mais terrestre versus mais marinho) e que podem alterar as estratégias exploratórias em determinadas regiões. Adicionalmente, a confirmação do tempo e persistência das condições mais úmidas, relativas aos ciclos do nível do mar, permitirá a identificação da distribuição, profundidade e perenidade dos lagos (potencial para desenvolver rocha geradora) e também permitir explicar e prever ocorrências de carvões.

A combinação da cicloestratigrafia e da quimioestratigrafia mostrou que existe ainda um grande potencial de pesquisa a ser explorado e compreendido nos registros sedimentares antigos.

Agradecimentos Agradecemos a Chevron Energy e a Petrobras pela permissão de publicar esta trabalho. Gostaríamos de agradecer Sidnei Rostirrola da Universidade Federal do Paraná, pela revisão desta versão em português e a Julia S. We-lner da Universidade de Rice e Kelly Dempster da Chevron Texaco pela revisão crítica do trabalho original em inglês. Agradecemos a George Griffith, Linda Lovell e Heriberto V. dos Santos pela confeç̧ão dos desenhos.

\section{Referências}

Azambuja Filho N.C. de 1990. The Oligo-Miocene turbidites and associated facies of Campos basin, offshore Brazil. Tese de Doutorado, Imperial College of London, Londres, $456 \mathrm{p}$.

Berger A.L. 1992. Astronomical theory of paleoclimates and the last glacial-interglacial cycle, Quaternary Science Reviews, 11: 571581.

Berger A.L. 1978. Long term variations of caloric insolation resulting from the Earth's orbital elements, Quaternary Research, 9: 139167.
Berger A.L. 1980. Milankovitch astronomical theory of paleoclimates: a modern review, Vistas in Astronomy, 24(2): 103-122.

Berger A.L., Loutre M.F. 1988. New insolation values for the climate of the last 10 million years, Scientific Rept. 1988/13, Inst. of Astron. and Geophys. Georges Lemaitre, Catholic University of Louvainla-Nueve.

Berger A.L., Loutre M.F., Laskar J. 1992. Stability of the astronomical frequencies over the earth's history for paleoclimate studies, Science 255:560-566. 
Blair T.C. 1986. Tectonic and hydrologic controls on cyclic alluvial fan, fluvial and lacustrine rift basin sedimentation, Jurassic-lowermost Cretaceous Todos Santos Formation, Chiapas, Mexico, J. Sed. Pet., 57: 845-862.

Bott M.H.P., Johnson G.A.L. 1967. The controlling mechanism of Carboniferous cyclic sedimentation, Quart. J. of the Geol. Soc. of London, 22: 421-441.

Bradley W.H. 1929. The varves and climate of the Green River Epoch, U.S. Geol. Surv. Prof. Pap., 154: 86-110.

Broecker W.S \& Denton G.H. 1989. The role of ocean-atmosphere reorganizations in glacial cycles. Geoch. Cosmoch. Acta, 53: 2465-2501.

Crook K.A.W. 1967. Tectonics, climate and sedimentation. In: 7th International Sedimentologic Cong. Proc., 1:1-3.

Dean W.E., Gardner J.V. 1986. Milankovitch cycles in Neogene deep sea sediment, Paleoceanography, 1:539-553.

De Boer P. L. \& Smith D. G. 1994. Orbital forcing and cyclic sequences. In: De Boer, P.L. \& Smith D.G. (ed.). 1994. Orbital forcing and cyclic sequences, International Association of Sedimentologists Special Publication, 19 Oxford Blackwell Scientific Publications, pp.: 1-14.

Fairbridge R.W. 1976. Effects of Holocene climatic change on some tropical geomorphic processes, Quaternary Research, 6:529-556.

Fischer A.G. 1986. Climatic rhythms recorded in strata, Annual Review Earth Planetary Science, 14:351-376.

Garner H.F. 1959. Stratigraphic-sedimentary significance of contemporary climate and relief in four regions of the Andes Mountains, Geol. Soc. Amer. Bull., 70: 1327-1368.

Gilbert G.K. 1895. Sedimentary measurement of Cretaceous time, $J$. Geol., 3:121-127.

Glennie, KW, 1984. Early Permian-Rotliegend. In: Glennie, KW, (ed.), Introduction to the Petroleum Geology of the North Sea, Blackwell Scientific Pub. Boston, Mass., pp.: 41-60.

Goldhammer R.K. Dunn P.A., Hardie L.A. 1987. High frequency glacioeustatic sea level oscillations with Milankovitch characteristics recorded in Middle Triassic platform carbonates in northern Italy, American Journal of Science, 287: 853-892.

Hayes, J. D., Imbrie, J., and Shackleton, N. J., 1976. Variations in the earth's orbit: pacemaker of the Ice Ages, Science, 194:1121-1132.

Herbert T.D. and Fischer A.G. 1986. Milankovitch climatic origin of the mid-Cretaceous black shale rhythms in central Italy, Nature, 321:739-743.

Imbrie J. and Imbrie K.P. 1979. Ice Ages - Solving the Mystery. Cambridge, Harvard University Press, 224 pp.

Imbrie J., Hays J.D., Martinson D., Mcintyre A., Mix A., Morley J., Pisia N., Prell W. \& Shackleton N.J. 1984. The orbital theory of Pleistocene climate: Support from a revised chronology of marine delta $\mathrm{O}^{18}$ record. In: Berger A.L. et al. (eds) Milankovitch and climate, Part 1, D. Reidel, London, pp.: 269-305.

Kalmykova M.A., Kashik D.S., Miklukho-Maklay K.V., Ukharskaya L.B. 1979. A complex utilization of biostratigraphic and cyclostratigraphic methods while studying the stratigraphy of marine Permian deposits of the Russian Platform. Ezhegodnik Vsesoyuznogo Paleontologicheskogo Obshchestva, 22: 235-252. Izdatel'stvo Nauka Leningradskoye Otdeleniye, St. Petersburg. USSR.
Kerr R.A. 1986. Mapping orbital effects on climate, Science, 234: 283284.

Kerr R.A. 1996. Ancient sea level swings confirmed, Science, 272: 1097-1098.

Kendall C.G.St.C., Moore P., Strobel J., Cannon R., Perlmutter M.A. , Bezdek J., Biswas G. 1991. Simulation of the sedimentary fill of basins. In: Franseen E.K., Watney W.K., Kendall, C.G.St.C. and Ross W. (eds.), Sedimentary Modeling, Kansas Geol. Survey Bull., 233:9-30.

Kolla V., Perlmutter M.A. 1993. Timing of turbidite sedimentation Mississippi fan. Amer: Assoc. Petrol. Geol. Bull., 77/7: 1129-1141.

Krynine P.D. 1942. Differential sedimentation and its products during one complete geosynclinal cycle. $I n$ : 1 st Congreso Panamericano de Ingeniera de Minas y Geologia, 2: pt. 1, 537-561.

Kukla G. and Gavin J. 1992. Insolation regime of the warm to cold transitions. In: Kukla, GJ, Went, E, (eds.), NATO ASI Ser., 13:307339.

Leopold L.B., Wolman M.G. and Miller J.P. 1964. Fluvial Processes in Geomorphology, San Francisco, Freeman and Co., 522 pp.

Le Tourneau. P.M. 1985. Alluvial fan developments in the Lower Jurassic Portland Formation, central Connecticut - implications for tectonics and climate. In: Robison G.P. and Frohlich A.J. (eds.), 2nd U.S.G.S. Workshop on the Mesozoic Basins of the Eastern U.S., U.S.G.S. Survey Circ. 946, pp.: 17-26.

Lockwood J.G. 1980. Milankovitch theory and ice ages. Progress in Phys. Geog., 4: 79-87.

Matthews R.K. and Frohlich C. 1991. Orbital forcing of low frequency glacioeustasy, Journal of Geophysics Research, 96 B4: 67976803.

Matthews M.D. and Perlmutter M.A. 1994. Global cyclostratigraphic analysis of the Green River basin. In: de Boer P.L. and Smith D.G. (eds.), Orbital forcing and cyclic sequences, Int. Assoc. Sed. Spec. Pub., 19:459-481.

Milankovitch M. 1941. Kanon der Erdbestranlung and seine anwendung auf das eiszeitenproblem (Canon of insolation and the ice age problem): Transactions of the Royal Serbian Academy, Belgrade, Spec. Pub. v. 132, Section of Mathematical and Natural Sciences, 33: 674 p. (English translation by the Israeli program for scientific translation. Published by the U.S. Dept. of Commerce and the National Science Foundation, Wash. D.C., NTIS Rept. SFCSICOMM (TT-67-514010-1-2), 1969, $507 \mathrm{pp}$.

Milliman J.D. and Syvitski J.P.M. 1992. Geomorphic/tectonic control of sediment discharge to the ocean: the importance of small mountainous rivers. Journal of Geology, 100:525-544.

Mitchum R.M. and Van Wagoner J.C. 1991. High frequency sequences and their stacking patterns: sequence-stratigraphic evidence of high frequency eustatic cycles, Sedimentary Geology, 70/24:131-160.

Moore T.L., Oglesby R.J., Perlmutter M.A., Matthews M.D., Plotnick R.E., Maasch K.A. 2000. Deciphering Orbital Maximum and Minimum States during the Pleistocene. In: Proc. G.S.A. Ann. Mtg., Reno, Nevada.

Newberry J.S. 1874. Circles of deposition in American sedimentary rocks. In: Amer. Assoc. for the Advancement of Science Proceedings, 22:185-96.

Olsen P.E. 1980. Fossil great lakes of the Newark Supergroup in New Jersey. In: Manspeizer, W, (ed), Field Studies of New Jersey 
Geology and Guide to Field Trips, 52nd Annual Meeting of the N.Y. State Geol. Assoc., Newark, N.J., Rutgers University, pp.: 352-398.

Park J. and Oglesby R.J. 1994. The effect of orbital cycles on Late and Middle Cretaceous climate: a comparative general circulation model study. In: De Boer P.L. \&. Smith D.G (eds.). Orbital forcing and cyclic sequences. International Association of Sedimentologists Special Publication, 19, Blackwell, pp.: 509-530.

Penck A. 1914. The shifting of climate belts, The Scottish Geographical Magazine, 30:281-293.

Perlmutter M.A. 1985. Deep water clastic reservoirs in the Gulf of Mexico: a depositional model, Geo-Marine Letters, 5:105-112.

Perlmutter M.A 1995. Using global cyclostratigraphy to predict lithofacies in continental and marine basins, Norwg. In: Petrol. Soc. Conf. on Predictive High Resolution Sequence Stratigraphy, Stavanger, Norway, p.16 A-C.

Perlmutter M.A., Brennan P.A., Hook S.C., Dempster K., Pasta D., 1995. Global cyclostratigraphic analysis of the Seychelles southern shelf for potential reservoir, seal and source rocks. In: Davis T.A., and Coffin M. (eds.), Paleoceanography and Environments of Exploration of the Indian Ocean Basin and Margins, Sed. Geol. Spec. Iss. 96/1-2:93-118.

Perlmutter M.A. and Matthews M.D. 1989. Global cyclostratigraphy: A Model. In: Cross, T. (ed.), Quantitative Dynamic Stratigraphy, Prentice Hall, N.J., pp.: 233-260.

Perlmutter M.A. and Matthews M.D. 1992. Global cyclostratigraphy. In: Nierenberg W.A. (ed.), Encyclopedia of Earth Systems Science, Academic Press, pp.: 379-393.

Perlmutter M.A. and Matthews M.D. 1994, Global cyclostratigraphy: predicting stratigraphic response to Milankovitch Cycle. In: Cecil C.B. and Edgar N.T. (eds.), Predictive stratigraphic analysis concept and applications. U.S.G.S. Survey Bull., 2110:67.

Perlmutter M.A., Radovich R.J., Matthews M.D., Plotnick R.E., Kendall C.G.St.C., 1998. The impact of high-frequency sedimentation cycles on stratigraphic interpretation. In: Sandvik K.O., Gradstein F.M., Milton N.J. (eds.), Sequence Stratigraphy, NPF Spec Pub 8, Elsevier Science B. V., Amsterdam, pp.: 141-70.

Perlmutter M.A. \& Plotnick R.E. 2002. Predictable variations in the marine stratigraphic record of the northern and southern hemispheres and reservoir potential. In: Armentrout J.M. and Rosen N.C (eds.), Sequence Stratigraphic Models for Exploration and Production: Evolving Methodology, Emerging Models and Application Histories, 22nd Ann. Gulf Coast Section Soc. for Sed. Geol. (SEPM). Proceeding, pp.: 231-256

Perlmutter M.A., Plotnick R.E. 2003. Hemispheric asymmetry of the marine stratigraphic record; conceptual proof of a unipolar icecap, in Cecil C.B. and Edgar N.T. (eds.), Climate Controls on Stratigraphy, Soc. for Sed. Geol. (SEPM) Spec. Pub 77. pp.: 5166.

Perlmutter M.A. and Azambuja Filho N.C. de 2005. Cyclostratigraphy,
In: Koutsoukos, E.A. (ed.). Applied Stratigraphy, Topics in Geobiology, volume 23, Springer, pp.: 301-338.

Posamentier H.W and Vail P.R. 1988. Eustatic controls on clastic deposition II - sequence and systems tract models. In: Wilgus C.K. et al. (ed.). Sea-level changes - an integrated approach. Soc. Econ. Paleont. Min. Spec. Pub. 42 Tulsa, pp.:125-154.

Schumm S,A. 1977. The Fluvial System, Wiley, New York, N.Y., 338 pp.

Schumm S.A., Brackenridge G.R. 1987. River responses. In: Ruddiman W.F., Wright H.E. Jr. (eds.), North America and Adjacent Oceans during the Last Deglaciation, The Geology of North America, v. K-3, GSA. Boulder, CO., pp.:221-240.

Summerfield M.A. and Hulton N.J. 1994. Natural controls of fluvial denudation rates in major world drainage basins. Journal of Geophysics Research, 99 (b7):13, 871-13, 883.

Twenhofel W.H. 1932. Treatise on Sedimentation, Williams and Wilkens Co., Baltimore, MD, 926 pp.

Vail P.R., Mitchum R.M., Thompson S. III 1977. Seismic stratigraphy and global changes of sea level, Part 3: Relative changes in sea level from coastal onlap. In: Payton C.E. (ed.), Seismic stratigraphy -Applications to Hydrocarbon Exploration, Amer. Assoc. of Petrol. Geol. Mem. 26, pp. 63-82.

Vail P.R., Audemard F., Bowman, S.A., Eisner, P.N. and Perze-Crus, C. 1991. The stratigraphic signatures of tectonics, eustasy and sedimentology - an overview. In: Einsele G., Ricken W. and Seilacher A. (eds.). Cycles and Events in Stratigraphy, Berlin, Heidelberg, New York, Springer-Verlag, pp.: 617-659.

Van Houton F.B. 1964. Cyclic lacustrine sedimentation, Upper Triassic Lockatong Formation, central New Jersey and adjacent Pennsylvania. Kansas St. Geol. Surv. Bull. 169, 2:497-531.

Veizer J., Jansen S,L, 1985, Basement and sedimentary recycling -2: time dimensions to global tectonics, Journal of Geology, 93: p.625-643.

Wanless H.R. and Shepherd F.P. 1936. Sea level and climate change related to late Paleozoic cycles, Geol. Soc. of Amer. Bull., 47:11771206.

Weller J.M. 1956. Argument for diastrophic control of late Paleozoic cyclothems, Amer. Assoc. of Petrol. Geol. Bull., 40:17-50.

Williams J.L. 1891. On cycles of sedimentation, Amer. Geol., 8: 315324.

Wilson L 1973. Variations in mean annual sediment yield as a function of mean annual precipitation, Amer. Jour. Sci. 278: 335-349.

Young S.W., Basu A., Mack G., Darnell N., Suttner L.J. 1975. Use of size-composition trends in Holocene soil and fluvial sand for paleoclimatic interpretation, In: 9th International Sedimentologic Cong. Proc., 1: 201-206. 